\title{
Germline Reprogramming of Heterochromatin in Plants
}

\author{
K.M. CREASEY AND R.A. MARTIENSSEN \\ Cold Spring Harbor Laboratory, Cold Spring Harbor, New York 11724 \\ Correspondence: martiens@cshl.edu
}

\begin{abstract}
Heterochromatin is composed of transposable elements (TEs) and other repeats and was once considered to be a wasteland of redundant genetic material and potentially harmful TE. Therefore, the reprogramming of heterochromatin and subsequent reactivation of TE in the immature seed and pollen is paradoxical in plants. Recent studies have shown that reactivation of TE occurs specifically in germline companion cells, the vegetative nucleus (VN) in pollen (Slotkin et al. 2009) and the endosperm in seed (Gehring et al. 2009). In the ovule, ARGONAUTE 9 (AGO9) not only has a role in silencing TE in the egg cell but also in preventing the formation of multiple asexual gametophytes (Olmedo-Monfil et al. 2010). We propose that reprogramming of heterochromatin in germline companion cells reveals TE in a controlled manner to expose them within the germline and, by the production of small interfering RNA (siRNA), ensures TE silencing in the next generation. We also propose that the mechanisms evolved to silence TE may actually promote sexual reproduction by inhibiting the formation of asexual gametes.
\end{abstract}

The botanist Emil Heitz (1928) first described "heterochromatin" as chromosomal material that remained condensed during interphase, in contrast to euchromatin, which is only condensed during mitosis. Traditionally, these chromatin regions were thought to differ in transcriptional activity, with euchromatin transcriptionally active and heterochromatin transcriptionally inert. However, during the last few years, abundant transcripts from heterochromatin have been discovered in germline cells and have been implicated in transposon control and germ-cell fate. In plants, and in many animal species, heterochromatin is mostly composed of transposable elements (TEs) and other repetitive DNA sequences, whereas euchromatin is mostly composed of genes. Biochemical analysis has revealed that euchromatin is characterized by transcriptionally active regulatory histone modifications, such as trimethylation of histone $\mathrm{H} 3$ lysine 4 ( $\mathrm{H} 3 \mathrm{~K} 4 \mathrm{me} 3)$, whereas heterochromatin is associated with transcriptionally inactive modifications, such as H3K9me3. In plants, heterochromatic DNA is heavily methylated in all three 5-methyl cytosine contexts - CG, CHG, and $\mathrm{CHH}$ (in which $\mathrm{H}$ is either $\mathrm{C}, \mathrm{T}$, or $\mathrm{A}$ ) (Henderson and Jacobson 2007), whereas euchromatin is associated with low levels of CG methylation (Lister et al. 2008) that often correlate with elevated gene transcription (Vaughn et al. 2007). Mammalian DNA methylation is mostly confined to CG contexts, although recently non-CG methylation has also been reported (Hawkins et al. 2010; Popp et al. 2010).

The function of heterochromatin was first indicated by the phenomenon of position effect variegation (PEV) in Drosophila, in which genes are silenced when juxtaposed with heterochromatin. It has since been shown that heterochromatin is important for eukaryotic genome integrity. Examples include centromere function, $\mathrm{X}$-chromosome inactivation, gene imprinting (Solter et al. 2004), paramutation (Della Vedova and Cone 2004), and epigenetic silencing of TE (Lippman et al. 2004).

TEs are subject to epigenetic silencing, presumably because of the detrimental effects associated with their activ- ity (Lippman et al. 2004). TEs can transpose, interrupt gene function, cause chromosome damage, and increase in copy number compared with host genes; therefore, maintaining TE silencing is vital for genome integrity. DNA and histone methyltransferases, histone deacetylases, and chromatin-remodeling complexes ensure heterochromatic silencing, presumably to limit the damaging effects of TE transposition. TE-related silencing across generations was first described in plants (McClintock 1957) and is associated with DNA methylation (Slotkin and Martienssen 2007), and recent examples in both plants and animals have suggested a role for RNA interference (RNAi) and histone modification (Vastenhouw et al. 2006; Josse et al. 2007; Malone and Hannon 2009; Teixeira et al. 2009). Here we review the proposal that reprogramming of heterochromatin in the germline reveals TEs by reactivating them, so as to silence them again in the next generation via short interfering RNAs (siRNAs) (Slotkin et al. 2009).

siRNAs corresponding to heterochromatic sequences guide histone methylation in protists, in plants (Henderson and Jacobson 2007), and in the fission yeast, Schizosaccharomyces pombe, where it is best understood (Grewal and Elgin 2007; Zaratiegui et al. 2007). Heterochromatic silencing in fission yeast is lost transiently during replication, allowing heterochromatic transcripts to accumulate. These transcripts are processed into siRNAs during the $\mathrm{S}$ phase of the cell cycle and direct the sequence-specific silencing machinery to reestablish heterochromatin in $\mathrm{G}_{2}$ (Kloc et al. 2008). Thus, the paradox of heterochromatin transcription (Volpe et al. 2002) is resolved, in that "reprogramming" in $S$ phase is necessary for silencing in $G_{2}$.

\section{RNA SILENCING AND HETEROCHROMATIC FORMATION IN PLANTS}

Plants, like other higher eukaryotes, have a more complex form of heterochromatin than fission yeast has and a sophisticated RNA silencing machinery. "RNA silencing" 
refers to a diverse set of RNA-directed processes that result in sequence-specific silencing at the transcriptional, posttranscriptional, or translational level. These processes include the formation of double-stranded RNA (dsRNA) via RNA-dependent RNA polymerases (RDR) from singlestranded RNA (ssRNA) precursors, the processing of the dsRNA into small interfering RNA (siRNA) by Dicer-like ribonucleases (DCL), and recruited by ssRNA-binding Argonaute proteins (AGO) and dsRNA-binding proteins (DRBs). A special class of small RNAs found in animals and plants, but not in yeast, namely, microRNAs (miRNAs), originates from imperfect stem-loop precursors, and is processed in Arabidopsis by DCL1 before loading onto AGO1 and other Argonaute proteins.

DNA methylation is conserved in vertebrates and some invertebrates, plants, and filamentous fungi, but not in Drosophila, Caenorhabditis elegans, and yeast. In plants, RNA-directed DNA methylation (RdDM) promotes de novo DNA methylation of cytosines regardless of their context, via DRM2 and CHROMOMETHYLASE 3, a CNG DNA methyltransferase that is also guided by histone modification (Law and Jacobsen 2010). Once in place, DNA methylation is maintained independently of RNAi by DECREASE IN DNA METHYLATION1 (DDM1), a SWI2/SNF2 ATPase, and by METHYLTRANSFERASE1 (MET1), a CG DNA methyltransferase (Slotkin and Martienssen 2007; Law et al. 2010). DNA methylation mutants $d d m 1$ and met 1 in Arabidopsis were discovered by the loss of DNA methylation at centromeric repeats (Vongs et al. 1993) and also lose methylation in most if not all classes of TE (Lippman and Martienssen 2004; Teixeira et al. 2009), resembling mutants in their mammalian homologs Lsh1 and Dnmt1 in this respect (Slotkin and Martienssen 2007). In $d d m 1$ mutants, heterochromatic regions become euchromatic, characterized by the loss of DNA methylation and gain of transcriptionally active histone modifications (Lippman et al. 2004). Interestingly, a novel class of 21nucleotide siRNA accumulates (Slotkin et al. 2009), indicating that TE reactivation and the emergence of novel siRNAs are both a consequence of losing DDM1.

Further analysis of tissue- and cell-specific Arabidopsis thaliana microarray data (Honys and Twell 2004; Pina et al. 2005; Schmid et al. 2005; Becker and Feijo 2007) revealed that TEs are unexpectedly reactivated during at least two developmental stages: in the immature seed and in pollen (Slotkin et al. 2009). This was surprising given that DDM1-dependent TE silencing was so efficient during vegetative development but not during the most crucial stages of the plant life cycle. The explanation lies in reprogramming events that are restricted to the germline.

\section{EPIGENETIC REPROGRAMMING IN THE GERMLINE}

Global epigenetic reprogramming occurs early in mammalian development, with the loss of DNA methylation and histone modifications in the primordial germ cells and in the embryo, and is thought to reset imprinting and other epigenetic marks in pluripotent cells (Branco et al. 2008; Surani et al. 2008). In plants, unlike animals, germ cells differentiate from adult somatic cells late in development. This presents the need for the resetting of epigenetic modifications that have been acquired during the plant life cycle. In plants, siRNAs from TEs are produced in gametophytes and developing seeds, and this accumulation is associated with changes in DNA methylation (Hsieh et al. 2009; Mosher et al. 2009; Slotkin et al. 2009). Reprogramming in mammals also results in transient activation of TEs (Sasaki and Matsui 2008). This activation coincides with the appearance of piwi-interacting RNA (piRNA) (Brennecke et al. 2007) as well as endogenous siRNA (Tam et al. 2008; Watanabe et al. 2008). The 25-29-nucleotide uniquely mapping piRNAs arise from specific heterochromatic loci that contain small fragments of various TEs thought to be responsible for silencing, but piRNAs and endogenous siRNAs also arise from repetitive TEs elsewhere in the genome (Lau et al. 2006; Aravin et al. 2008). It is therefore possible that TE reprogramming has a similar function in the mammalian germline as in plants (which do not seem to have piRNAs), in that TE activation results in accumulation of corresponding small RNAs (Slotkin et al. 2009). Interestingly, piRNAs can direct remethylation in the Mus musculus male germline (Carmell et al. 2007; Kuramochi-Miyagawa et al. 2008), suggesting that RNA-dependent DNA methylation is also conserved. Endogenous siRNA may have a similar role in Drosophila oocytes even in the absence of DNA methyllation (Malone et al. 2009).

\section{EPIGENETIC REPROGRAMMING OF HETEROCHROMATIN IN POLLEN}

The male gametophyte in plants, the pollen grain, differentiates late during plant development. Following meiosis, the first microspore division separates the vegetative nucleus (VN) from the generative nucleus, and the generative nucleus divides again to produce two sperm cells (SCs). Chromatin within the SC nuclei is compact with relatively little gene expression, whereas $\mathrm{VN}$ chromatin is less condensed and does not contribute genetic material to the next generation. Reexamination of Arabidopsis expression profiling data (Schmid et al. 2005) revealed that a diverse set of TE families, independent of chromosomal position, became transcriptionally reactivated in mature wild-type pollen (Slotkin et al. 2009). Gene-trap and enhancer-trap lines inserted into TEs (Sundaresan et al. 1995) were used to confirm that the TEs were silent in most cells, but not in the pollen grain cytoplasm, confirming TE activity in the pollen. Independent transcriptional profiling through fluorescence-activated cell sorting revealed that TEs were up-regulated only in the $\mathrm{VN}$ and not in the SC (Borges et al. 2008). Transposon display revealed that novel transposition events occurred in pollen DNA but were not detected in the $\mathrm{F}_{1}$ progeny, further indicating that they did not occur in sperm cells.

$D D M 1$ is specifically required for TE methylation and association with H3K9me2 (Singer et al. 2001; Gendrel et al. 2002; Lippman et al. 2004), and thus the localization of DDM1 was determined in pollen using DDM1-tagged green fluorescent protein (GFP) (Slotkin et al. 2009). 


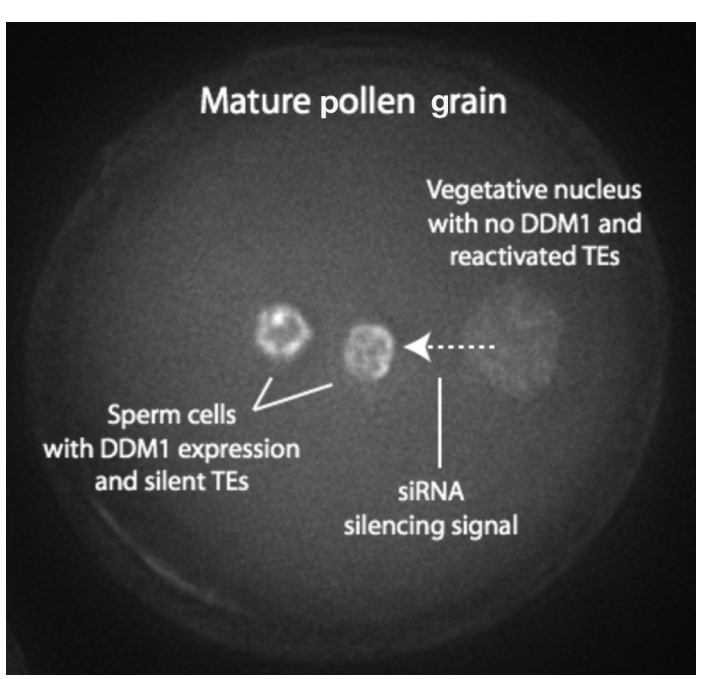

Figure 1. Heterochromatin reprogramming and small RNA silencing in pollen. In this model, loss of DDM1 (and MET1) results in reprogramming of heterochromatin in the vegetative nucleus. This activates TEs and results in the production of a small RNA silencing signal that makes its way into the sperm. In this way, heterochromatin acts as a reservoir of TE sequences used to recognize the same TE in the germline.

DDM1-GFP was absent in the VN but expressed in the SC, in agreement with $\mathrm{TE}$ reactivation being confined to the VN. However, although the largest family of TEs in $A$. thaliana, Athila retrotransposons, was reactivated in the $\mathrm{VN}$, the corresponding 21-nucleotide siRNAs accumulated in the SC. These results suggested that loss of DDM1 resulted in siRNA accumulation in pollen, which was subsequently translocated into the sperm (Fig. 1) (Slotkin et al. 2009).

To test movement of sRNAs from the VN to the sperm, an artificial microRNA (amiRNA) was expressed in the $\mathrm{VN}$ that targeted a GFP-reporter transgene in the SC, using VN- and SC-specific promoters and amiRNA (Engel et al. 2005; Schwab et al. 2009). In homozygous lines encoding the GFP amiRNA, but not in control lines, the GFP signal was dramatically down-regulated in the SC (Slotkin et al. 2009). This indicated that amiRNA, at least, could silence genes in the SC when expressed in the VN.

In conclusion, 21- to 22-nucleotide siRNAs from pericentromeric retrotransposons, as well as other classes of transposons, accumulate in $d d m 1$ and met 1 mutants and in pollen when DDM1 and MET1 are down-regulated in the VN (Slotkin et al. 2009). The same siRNAs appear in plant cell culture, also known to undergo epigenetic reprogramming (Tanurdzic et al. 2008). Epigenetic reprogramming of heterochromatin in the pollen leads to the accumulation of mobile siRNAs that promote TE silencing in the sperm.

\section{SIRNA SILENCING IN IMMATURE OVULES}

During ovule development, the megaspore mother cell undergoes a meiotic division producing four megaspores. The maternally derived gamete is produced from one functional megaspore while the remaining three megaspores degenerate. The haploid female gametophyte de- velops, surrounded by the diploid tissue of the ovule, and consists of one egg cell, one diploid central cell (two fused polar nuclei), two synergid cells, and three antipodal cells. The egg cell and central cell are fertilized by the two sperm cells to give rise to the embryo and endosperm in the developing seed. In aposporous plant species, additional diploid gametophytes differentiate adjacent to the functional megaspore in premeiotic and postmeiotic ovules. Subsequent parthenogenesis results in asexual reproduction via apomixis.

The most abundant argonaute genes expressed in developing ovules and anthers encode AGO9 and AGO5 (Schmid et al. 2005), which are closely related to AGO4 and AGO1 in vegetative cells, respectively. RNA isolation from immature ovules and in situ hybridization revealed that $A G O 9$ is initially expressed in the somatic cells in the apical region of the premeiotic wild-type ovule, but not in the haploid megaspores, the megaspore mother cell (MMC), or the developing female gametophyte before or following cellularization (Olmedo-Monfil et al. 2010). At the four-nuclear stage of female gametogenesis, $A G O 9$ localized to the outer integument and at the cellular boundary between the sporophyte and gametophyte. Similar localization was observed during anther development, with $A G O 9$ localized in the cytoplasm of the microsporophytes following meiosis, and later confined to the VN surrounding the SC.

Using the same gene-trap and enhancer-trap lines inserted into TEs (Sundaresan et al. 1995), ago 9 mutants were found to express TEs very strongly in egg cells, but not in the surrounding ovule and not in wild-type ovules (Olmedo-Monfil et al. 2010). This indicated that RNAi silenced TEs in the female germline, but that AGO9 likely acted at a distance, resembling pollen in this respect. sRNA was isolated following immunoprecipitation with an AGO9 antibody from wild-type gynoecia. Of those reads that mapped to the Arabidopsis genome, 79\% were 24 nucleotides and the remainder were 21 and 22 nucleotides in length. The 24-nucleotide siRNAs derive from retrotransposons, including AtGypsy, Athila, CACTA, LINE, and Mutator elements. The remaining 21-nucleotide siRNAs derive from miRNAs $(3.2 \%)$ and protein-coding genes (14.5\%) (Olmedo-Monfil et al. 2010).

Extensive phenotypic analysis of premeiotic ovules from three independent knockout lines of $A G O 9$ revealed extra abnormally large subepidermal cells. The identity of these abnormal cells in ago9-3 ovules was further characterized by callose deposition, a marker for meiotic cells (Webb and Gunning 1990). During and post meiosis, callose was detected in the intermediate walls of the single meiotic product and degenerate neighboring cells, but not in the abnormally enlarged cells. Following gametogenesis, the functional megaspore identity marker pFM2 is normally expressed only in the products of meiosis, but was also expressed in a cluster of adjacent cells in ago9-3 ovules. These results indicate that $A G O 9$ controls female gamete formation and restricts the formation and differentiation of multiple female gametic cells within the ovule.

RDR6 and SGS3 are required for the biogenesis of 21nucleotide trans-acting siRNA (tasiRNA), and we have found that RDR6 is also required for the accumulation of 
21-nucleotide easiRNA (epigenetically activated siRNA) from Athila elements in $d d m 1$ mutants (RK Slotkin and RA Martienssen, unpubl.). In both sgs3-11 and rdr6-11 postmeiotic mutant ovules, two independent female gametophytes were also observed (Olmedo- Monfil et al. 2010). Female gametophyte identity was subsequently confirmed using the pFM2 expression marker.

\section{SIRNA SILENCING IN IMMATURE SEEDS}

A role for small RNA in immature seeds has been revealed by small RNA sequencing from developing $\mathrm{F}_{1}$ hybrid seed from crosses between two different inbred accessions of Arabidopsis, Landsberg and Columbia, that differ in their complement of siRNA. Samples were prepared from seeds in which the embryos had been removed, leaving endosperm and maternal seed coats (Mosher et al. 2009). Sequencing revealed that 24-nucleotide siRNAs from the maternal parent could be detected in these samples and that these siRNAs depended on the plant-specific polymerase RNA polymerase IV (Pol IV) for their biogenesis. Heterozygous Pol IV mutants gave rise to intermediate levels of siRNA, leading to the conclusion that the siRNAs arose primarily in the endosperm, half of which would inherit the mutant allele from their maternal parents (Mosher et al. 2009). It is likely, then, that these 24-nucleotide siRNAs arise from endosperm tissue, although small RNAs from maternal seed coat tissue, derived from the surrounding ovule, would also be included in these libraries.

Interestingly, endosperm and embryo differ in DNA methylation patterns, with the endosperm being generally depleted in CG methylation, whereas both endosperm and embryo are enriched in RNAi-dependent CHH methylation patterns (Gehring et al. 2009; Hsieh et al. 2009). Analogous to pollen, it is possible that small RNAs are generated from unmethylated TEs in the endosperm, to guide methylation in the embryo. MET1 is down-regulated in the endosperm, consistent with this idea (Jullien and Berger 2010; Martienssen 2010b). Active demethylation mediated by DEMETER DNA glycosylases also has a major role in genome-wide demethylation in the endosperm (Hsieh et al. 2009), but is only expressed at a low level in pollen.

\section{ROLE OF SIRNAS IN INHERITANCE AND GERM-CELL FATE}

Reprogramming of heterochromatin within the germline results in the accumulation of siRNAs within the companion cells of the ovule and pollen that can act noncell autonomously to silence TEs in sperm and egg cells, respectively (Slotkin et al. 2009; Olmedo-Monfil et al. 2010). A similar mechanism likely influences DNA methylation in the embryo and endosperm after fertilization. Remarkably, this TE-silencing mechanism appears to inhibit asexual reproduction, suggesting that these same TE small RNAs might influence germ-cell fate. Thus, TEs have retained the ability to generate germline siRNAs during evolution, despite their negative influence on TE expression. In the absence of selection, recombination between transposed elements is required for increases in TE copy number, so that TEs can propagate more effectively in sexually reproducing species (Hickey 1993). Therefore, it would appear that RNAi-directed inhibition of asexual reproduction might actually benefit TEs. For this reason, this mechanism can be seen as allowing TEs an advantage over the host genome.

Small RNAs may also make a parental epigenetic contribution to the next generation, reminiscent of their role in hybrid dysgenesis (Malone and Hannon 2009), such that small RNAs from one parent may be required to silence incoming transposons from the other (Klattenhoff and Theurkauf 2008). In both mammals and plants, germline siRNAs direct sequence-specific epigenetic silencing and could potentially exert a parent-specific influence on the developing progeny. It is, therefore, interesting to speculate that, like genome imprinting, reprogramming of heterochromatin could create a parentspecific defensive barrier against interspecific and interploid hybridization (Martienssen 2010b). Given their mobility, it is even possible that small RNAs from somatic cells might find their way into the germline and then into the next generation, raising the specter of Lamarckian inheritance, as long as their expression was sensitive to the environment, as many TE sequences have been shown to be (Martienssen 2010a).

\section{CONCLUSION}

Germline companion cells, such as the VN in the pollen as well as the endosperm in developing seed, do not contribute genetic information to the next generation, but guide sperm cells to the ovule and provide nourishment to the developing embryo, respectively. In developing gametophytes, reprogramming of heterochromatin leads to the reactivation of TEs and accumulation of siRNAs. In this light, heterochromatin can be seen as a reservoir of TE sequences, released into the germline to reveal valuable siRNAs. These siRNAs can recognize and silence TEs, but also influence germ-cell fate in a way that promotes their propagation through sexual reproduction.

\section{ACKNOWLEDGMENTS}

We thank Dr. Milos Tanurdzic for critical reading of the manuscript and members of the Martienssen laboratory for discussion and sharing unpublished data. We also thank R. Keith Slotkin and Jean-Philippe Vielle Calzada for important discussions. Work in the authors' laboratory is supported by a grant from the National Institutes of Health (ARRA-R01GM067014).

\section{REFERENCES}

Aravin AA, Sachidanandam R, Bourc'his D, Schaefer C, Pezic D, Toth KF, Bestor T, Hannon GJ. 2008. A piRNA pathway primed by individual transposons is linked to de novo DNA methylation in mice. Mol Cell 31: 785-799.

Becker JD, Feijo JA. 2007. How many genes are needed to make a pollen tube? Lessons from transcriptomics. Ann Bot 100: $1117-1123$. 
Borges F, Gomes G, Gardner R, Moreno N, McCormick S, Feijo JA, Becker JD. 2008. Comparative transcriptomics of Arabidopsis sperm cells. Plant Physiol 148: 1168-1181.

Branco MR, Oda M, Reik W. 2008. Safeguarding parental identity: Dnmt1 maintains imprints during epigenetic reprogramming in early embryogenesis. Genes Dev 22: 1567-1571.

Brennecke J, Aravin AA, Stark A, Dus M, Kellis M, Sachidanandam R, Hannon GJ. 2007. Discrete small RNA-generating loci as master regulators of transposon activity in Drosophila. Cell 128: 1089-1103.

Carmell MA, Girard A, van de Kant HJ, Bourc'his D, Bestor TH, de Rooij DG, Hannon GJ. 2007. MIWI2 is essential for spermatogenesis and repression of transposons in the mouse male germline. Dev Cell 12: 503-514.

Della Vedova C, Cone K. 2004. Paramutation: The chromatin connection. Plant Cell 16: 1358-1364.

Engel M, Holmes-Davis R, McCormick S. 2005. Green sperm. Identification of male gamete promoters in Arabidopsis. Plant Physiol 138: 2124-2133.

Gehring M, Bubb KL, Henikoff S. 2009. Extensive demethylation of repetitive elements during seed development underlies gene imprinting. Science 324: 1447-1451.

Gendrel AV, Lippman Z, Yordan C, Colot V, Martienssen RA. 2002. Dependence of heterochromatic histone H3 methylation patterns on the Arabidopsis gene DDM1. Science 297: 1871-1873.

Grewal S, Elgin S. 2007. Transcription and RNA interfence in the formation of heterochromatin. Nature 447: 399-406.

Hawkins RD, Hon GC, Lee LK, Ngo Q, Lister R, Pelizzola M, Edsall LE, Kuan S, Luu Y, Klugman S, et al. 2010. Distinct epigenomic landscapes of pluripotent and lineage-committed human cells. Cell Stem Cell 6: 479-491.

Heitz E. 1928. Das heterochromatin der Moose. Jahrb Wiss Botanik 69: 762-818.

Henderson I, Jacobson S. 2007. Epigenetic inheritance in plants. Nature 447: 418-424.

Hickey DA. 1993. Molecular symbionts and the evolution of sex. $J$ Hered 84: 410-414.

Honys D, Twell D. 2004. Transcriptome analysis of haploid male gametophyte development in Arabidopsis. Genome Biol 5: R85. doi: 10.1186/gb-2004-5-11-r85.

Hsieh TF, Ibarra CA, Silva P, Zemach A, Eshed-Williams L, Fischer RL, Zilberman D. 2009. Genome-wide demethylation of Arabidopsis endosperm. Science 324: 1451-1454.

Josse T, Teysset L, Todeschini A, Sidor C, Anxolabehere D, Ronsseray S. 2007. Telomeric trans-silencing: An epigenetic repression combining RNA silencing and heterochromatin formation. PLoS Genet 3: 1633-1643.

Jullien PE, Berger F. 2010. DNA methylation reprogramming during plant sexual reproduction? Trends Genet 26: 394-399.

Klattenhoff C, Theurkauf W. 2008. Biogenesis and germline functions of piRNAs. Development 135: 3-9.

Kloc A, Zaratiegui M, Nora E, Martienssen R. 2008. RNA interference guides histone modification during the $\mathrm{S}$ phase of chromosomal replication. Curr Biol 18: 490-495.

Kuramochi-Miyagawa S, Watanabe T, Gotoh K, Totoki Y, Toyoda A, Ikawa M, Asada N, Kojima K, Yamaguchi Y, Ijiri TW, et al. 2008. DNA methylation of retrotransposon genes is regulated by Piwi family members MILI and MIWI2 in murine fetal testes. Genes Dev 22: 908-917.

Lau NC, Seto AG, Kim J, Kuramochi-Miyagawa S, Nakano T, Bartel DP, Kingston RE. 2006. Characterization of the piRNA complex from rat testes. Science 313: 363-367.

Law JA, Jacobsen SE. 2010. Establishing, maintaining and modifying DNA methylation patterns in plants and animals. Nat Rev Genet 11: 204-220.

Law JA, Ausin I, Johnson LM, Vashisht AA, Zhu JK, Wohlschlegel JA, Jacobsen SE. 2010. A protein complex required for polymerase $\mathrm{V}$ transcripts and RNA-directed DNA methylation in Arabidopsis. Curr Biol 20: 951-956.

Lippman Z, Martienssen R. 2004. The role of RNA interference in heterochromatic silencing. Nature 431: 364-370.

Lippman Z, Gendrel AV, Black M, Vaughn MW, Dedhia N, McCombie WR, Lavine K, Mittal V, May B, Kasschau KD, et al.
2004. Role of transposable elements in heterochromatin and epigenetic control. Nature 430: 471-476.

Lister R, O'Malley RC, Tonti-Filippini J, Gregory BD, Berry CC, Millar AH, Ecker JR. 2008. Highly integrated single-base resolution maps of the epigenome in Arabidopsis. Cell 133: 523 536.

Malone CD, Hannon GJ. 2009. Molecular evolution of piRNA and transposon control pathways in Drosophila. Cold Spring Harb Symp Quant Biol 74: 225-234.

Malone CD, Brennecke J, Dus M, Stark A, McCombie WR, Sachidanandam R, Hannon GJ. 2009. Specialized piRNA pathways act in germline and somatic tissues of the Drosophila ovary. Cell 137: 522-535.

Martienssen R. 2010a. Molecular biology. Small RNA makes its move. Science 328: 834-835.

Martienssen RA. 2010b. Heterochromatin, small RNA and postfertilization dysgenesis in allopolyploid and interploid hybrids of Arabidopsis. New Phytol 186: 46-53.

McClintock B. 1957. Controlling elements and the gene. Cold Spring Harb Symp Quant Biol 21: 197-216.

Mosher RA, Melnyk CW, Kelly KA, Dunn RM, Studholme DJ, Baulcombe DC. 2009. Uniparental expression of PolIV-dependent siRNAs in developing endosperm of Arabidopsis. Nature 460: $283-286$.

Olmedo-Monfil V, Duran-Figueroa N, Arteaga-Vazquez M, Demesa-Arevalo E, Autran D, Grimanelli D, Slotkin RK, Martienssen RA, Vielle-Calzada JP. 2010. Control of female gamete formation by a small RNA pathway in Arabidopsis. Nature 464: 628-632.

Pina C, Pinto F, Feijo JA, Becker JD. 2005. Gene family analysis of the Arabidopsis pollen transcriptome reveals biological implications for cell growth, division control, and gene expression regulation. Plant Physiol 138: 744-756.

Popp C, Dean W, Feng S, Cokus SJ, Andrews S, Pellegrini M, Jacobsen SE, Reik W. 2010. Genome-wide erasure of DNA methylation in mouse primordial germ cells is affected by AID deficiency. Nature 463: 1101-1105.

Sasaki H, Matsui Y. 2008. Epigenetic events in mammalian germcell development: Reprogramming and beyond. Nat Rev Genet 9: 129-140.

Schmid M, Davison T, Henz S, Papre U, Demar M, Vingron M, Scholkopf B, Weigel D, Lohmann J. 2005. A gene expression map of Arabidopsis thaliana development. Nat Genet 37: 501-506.

Schwab R, Maizel A, Ruiz-Ferrer V, Garcia D, Bayer M, Crespi M, Voinnet O, Martienssen RA. 2009. Endogenous TasiRNAs mediate non-cell autonomous effects on gene regulation in Arabidopsis thaliana. PLoS One 4: e5980. doi: 10.1371/journal. pone.0005980.

Singer T, Yordan C, Martienssen RA. 2001. Robertson's Mutator transposons in $A$. thaliana are regulated by the chromatin-remodeling gene Decrease in DNA Methylation (DDM1). Genes Dev 15: 591-602.

Slotkin RK, Martienssen R. 2007. Transposable elements and the epigenetic regulation of the genome. Nat Rev Genet 8: 272 285.

Slotkin RK, Vaughn M, Borges F, Tanurdzic M, Becker JD, Feijo JA, Martienssen RA. 2009. Epigenetic reprogramming and small RNA silencing of transposable elements in pollen. Cell 136: 461-472.

Solter D, Hiiragi T, Evsikov A, Moyer J, De Vries W, Peaston A, Knowles B. 2004. Epigenetic mechanisms in early mammalian development. Cold Spring Harb Symp Quant Biol 69: 11-17.

Sundaresan V, Springer P, Volpe T, Haward S, Jones J, Dean C, Ma H, Martienssen R. 1995. Patterns of gene action in plant development revealed by enhancer trap and gene trap transposable elements. Genes Dev 9: 1797-1810.

Surani MA, Durcova-Hills G, Hajkova P, Hayashi K, Tee WW. 2008. Germ line, stem cells, and epigenetic reprogramming. Cold Spring Harb Symp Quant Biol 73: 9-15.

Tam OH, Aravin AA, Stein P, Girard A, Murchison EP, Cheloufi S, Hodges E, Anger M, Sachidanandam R, Schultz RM, et al. 2008. Pseudogene-derived small interfering RNAs regulate gene expression in mouse oocytes. Nature 453: 534-538. 
Tanurdzic M, Vaughn MW, Jiang H, Lee TJ, Slotkin RK, Sosinski B, Thompson WF, Doerge RW, Martienssen RA. 2008. Epigenomic consequences of immortalized plant cell suspension culture. PLoS Biol 6: 2880-2895.

Teixeira FK, Heredia F, Sarazin A, Roudier F, Boccara M, Ciaudo C, Cruaud C, Poulain J, Berdasco M, Fraga MF, et al. 2009. A role for RNAi in the selective correction of DNA methylation defects. Science 323: 1600-1604.

Vastenhouw NL, Brunschwig K, Okihara KL, Muller F, Tijsterman M, Plasterk RH. 2006. Gene expression: Long-term gene silencing by RNAi. Nature 442: 882 .

Vaughn MW, Tanurdzic M, Lippman Z, Jiang H, Carrasquillo R, Rabinowicz PD, Dedhia N, McCombie WR, Agier N, Bulski A, et al. 2007. Epigenetic natural variation in Arabidopsis thaliana. PLoS Biol 5: e174. doi: 10.1371/journal.pbio.0050174.
Volpe TA, Kidner C, Hall IM, Teng G, Grewal SI, Martienssen RA. 2002. Regulation of heterochromatic silencing and histone H3 lysine-9 methylation by RNAi. Science 297: 1833-1837.

Vongs A, Kakutani T, Martienssen RA, Richards EJ. 1993. Arabidopsis thaliana DNA methylation mutants. Science 260: 1926-1928.

Watanabe T, Totoki Y, Toyoda A, Kaneda M, Kuramochi-Miyagawa S, Obata Y, Chiba H, Kohara Y, Kono T, Nakano T, et al. 2008. Endogenous siRNAs from naturally formed dsRNAs regulate transcripts in mouse oocytes. Nature 453: 539-543.

Webb M, Gunning B. 1990. Embryo sac development in Arabidopsis thaliana. I. Megasporogenesis, including the microtubular cytoskeleton. Sex Plant Reprod 3: 244-256.

Zaratiegui M, Irvine DV, Martienssen RA. 2007. Noncoding RNAs and gene silencing. Cell 128: 763-776. 


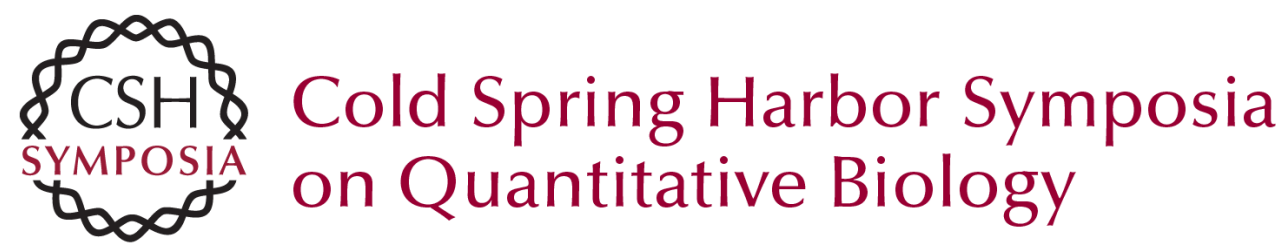

\section{Germline Reprogramming of Heterochromatin in Plants}

K.M. Creasey and R.A. Martienssen

Cold Spring Harb Symp Quant Biol 2010 75: 269-274 originally published online April 18, 2011 Access the most recent version at doi:10.1101/sqb.2010.75.064

References This article cites 56 articles, 20 of which can be accessed free at: http://symposium.cshlp.org/content/75/269.full.html\#ref-list-1

\section{License}

Email Alerting Receive free email alerts when new articles cite this article - sign up in Service the box at the top right corner of the article or click here. 